\title{
Article \\ Agreeing and Moving across Traces: On Why Lower Copies May Be Transparent or Opaque
}

\author{
Jairo Nunes
}

Citation: Nunes, J. Agreeing and Moving across Traces: On Why

Lower Copies May Be Transparent or Opaque. Philosophies 2022, 7, 3.

https://doi.org/10.3390/

philosophies7010003

Academic Editor: Peter Kosta

Received: 3 November 2021

Accepted: 15 December 2021

Published: 24 December 2021

Publisher's Note: MDPI stays neutral with regard to jurisdictional claims in published maps and institutional affiliations.

Copyright: (C) 2021 by the author. Licensee MDPI, Basel, Switzerland. This article is an open access article distributed under the terms and conditions of the Creative Commons Attribution (CC BY) license (https:// creativecommons.org/licenses/by/ $4.0 /)$.
Departamento de Linguística, Faculdade de Filosofia, Letras e Ciências Humanas, Universidade de São Paulo, São Paulo 05508-900, Brazil; jmnunes@usp.br

\begin{abstract}
Within Minimalism, traces are often taken to be transparent for agreement and movement across them, which raises the question of how this could be properly accounted for within the copy theory of movement. This paper examines $w h$-traces in multiple $w h$-questions and argues that traces (lower copies) may or may not induce intervention effects depending on whether or not they are fully specified.
\end{abstract}

Keywords: copy theory; minimality; feature valuation; superiority; edge features; multiple wh-questions

\section{Introduction}

One of the several ground-breaking contributions of Conditions on Transformations [1] was the proposal that a movement operation displacing a syntactic object $\alpha$ from the position $X$ to the position $Y$ leaves behind a trace "controlled" by $\alpha$. The postulation of traces allowed a considerable simplification of the EST framework (making it possible to dispense with rule ordering, for instance) and expanded the empirical coverage of the model (accounting for wanna-contraction phenomena, for instance; see e.g., [2]). Trace theory was later incorporated into GB [3], becoming one of its solid pillars. Different types of traces were identified, traces were computed in different modules, and there was even a specially dedicated module to inspect their licensing (the ECP). With the development of the Minimalist Program [4], the key role played by traces in restricting the theoretical apparatus and providing a device to assign interpretation to "dislocated" constituents was essentially maintained, but the overall house-cleaning entertained by minimalism led to a reevaluation of traces as theoretical primitives. In $[4,5]$, it is argued that a trace should actually be a copy of a dislocated constituent and that its properties, distribution, and interpretation should be independently derived.

Like trace theory in its birth, the copy theory has promoted a considerable simplification of the theoretical apparatus (the elimination of non-interface levels of representation, for instance), while enlarging the empirical landscape (making it possible to account for the pronunciation of lower copies or multiple copies, for instance; see e.g., [6], the papers in [7], and references therein). The task of deducing all the properties previously ascribed to traces is very challenging, though, for one is always tempted to describe these properties by referring to lower copies as opposed to the highest copy. However, if distinctions among different copies are not independently motivated, trace theory is being reintroduced through the back door.

In this paper I discuss one such challenge. In [8-10] it is argued that traces (lower copies) do not induce intervention effects for agreement or movement across them, suggesting that only the entire chain can do so. My point here is not to refute the argument itself, but to offer an alternative explanation for why lower copies may behave in this manner. The alternative will be shown to cover the original cases discussed and pave the way to account for much of the crosslinguistic variation involved in multiple wh-questions. 
The paper is organized as follows. In Section 2, I present the account in [8-10] for why lower copies do not induce minimality effects and outline an alternative. Pursuing this alternative requires a more detailed inspection of intermediate traces and in order to do so, in Section 3 I present the account of successive cyclic $\mathrm{A}^{\prime}$-movement in [11], building on the proposals in $[8,12]$. In Section $4 \mathrm{I}$ then argue that the proposal in [11] that the lexical host of edge features (features that trigger successive cyclic $\mathrm{A}^{\prime}$-movement) has syntactic consequences proves especially relevant to the issue of movement across traces. More specifically, I argue that the value of the edge feature of a given copy determines whether or not the copy induces a superiority effect and that an edge feature hosted by a phase head may independently enforce or void superiority effects. Section 5 offers some concluding remarks.

\section{Agreeing and Moving across Traces}

Consider the data in (1) below. (1a) shows that in Icelandic, a matrix verb with a quirky subject may agree with an embedded nominative. (1b) in turn shows that an intervening quirky subject blocks an agreement relation between a matrix verb and an embedded nominative. Finally, (1c) shows that movement of an embedded quirky subject across a dative experiencer in the matrix clause is not allowed.

(1) Icelandic:

$$
\begin{aligned}
& \text { a. Mér póttu/pótti [pær vera duglegar]. } \\
& \text { me(D) thought(3pl/dft) they(Npl) be industrious } \\
& \text { 'I thought they were industrious.' } \\
& \text { b. Mér virðist/??virðast [Jóni líka hestarnir]. } \\
& \text { me(D) seems(sg/??pl) John(D) to-like horses(N) } \\
& \text { 'It seems to me that John likes horses.' } \\
& \text { c. *Jóni virðist mér líka hestarnir. } \\
& \text { John(D) seems me(D) to-like horses } \\
& \text { 'John seems to me to like horses.' }
\end{aligned}
$$

The analysis of these data in [8] is as in (2) below, where the relevant elements are in boldface. The ungrammaticality of $(2 b)$ and $(2 c)$ is not surprising: the intervening embedded quirky subject in $(2 \mathrm{~b})$ blocks the agreement between the matrix $\mathrm{T}$ and the embedded nominative argument and the intervening experiencer in (2c) blocks A-movement of the embedded quirky subject to the matrix clause. By contrast, (2a) is unexpected, as the trace of the quirky subject within the matrix $v \mathrm{P}$ should block the agreement between the matrix $\mathrm{T}$ and the embedded nominative subject. The long distance agreement in (2a) is even more intriguing if seen from the perspective of the copy theory. As a copy of the moved experiencer, the trace in (2a) should induce the same blocking effect as the embedded subject in (2b), contrary to fact.

(2) $[8]$ (p. 130)

a. me(dat) thought(pl) [ $t_{\mathrm{me}}[$ they (pl,nom) be industrious]]

b. * me(dat) seem(pl) [ $t_{\mathrm{me}}[\mathrm{John}(\mathrm{dat})$ to like horse(pl,nom)]]

c. *John seems(sg) me(dat) [ $t_{\text {John }}$ to like horses]

Chomsky [8] (p. 131) accounts for the contrast between (2a), on the one hand, and $(2 b)$ and $(2 c)$, on the other, by proposing that "it is only the head of the A-chain that blocks matching ( ... ). A-movement traces are 'invisible' to the probe-goal-associate relation; or from another perspective, the A-chain itself (regarded as a set of occurrences of $\alpha$ ) constitutes the barrier". Notice that although Chomsky ascribes distinct properties to the highest copy as opposed to lower copies, he offers a sound conceptual argument as to why this should be so. The idea is that it is chains and not chain links that should be computed for minimality purposes.

Although very reasonable, the proposal does not capture all the relevant cases examined by Chomsky. Consider, for example, the contrast between the derivations in (3a) and (3b), discussed in [9]. 
(3) $\quad[9]$ (p. 26)

a. (guess) whatobj [Johnsubj T [op tobj [tsubj read tobj]]]

b. [Johnsubj T [or thatobj [tsubj read tobj]]]

The derivation sketched in $(3 \mathrm{~b})$, with movement of the object to the outer [Spec, vP], crashes, but the one in (3a), where the object further moves to [Spec,CP], converges. Chomsky [9] attempts to assimilate the contrast in (3) to the contrast in (2). The gist of the proposal is that movement of the subject to $[\mathrm{Spec}, \mathrm{TP}]$ is blocked by the moved object in $(3 b)$, but not in (3a), because the relevant intervening element in (3a) is a trace. Observe that upon close inspection, the rationale for why only the highest copy induces minimality effects discussed with respect to (2) is not valid in (3b). Recall that agreement between the matrix $\mathrm{T}$ and the embedded subject across the trace of the experiencer in (2a) was taken to be grammatical because the relation did not span across all occurrences of the experiencer; crucially, the copy in the matrix [Spec,TP] in (2a) does not count as an intervener as it is not c-commanded by the matrix T. All things being equal, the same should be said with respect to (3b): the subject does not cross all the occurrences of that, as it does not cross the occurrence in the object position. The derivation should thus converge, contrary to fact.

Chomsky [9] in fact suggests that the contrast between (3a) and (3b) could be accounted for if the notion of equidistance restated in the Agree-based model as in (4a) were redefined as in (4b).

(4) a. Terms of the edge of HP are equidistant from probe P. [9] (p. 27)

b. The phonological edge of HP is accessible to probe P. [9] (p. 28)

If (4b) is assumed instead of (4a), $T$ in (3a) can attract the subject because the trace of wh-object in $[\mathrm{Spec}, v \mathrm{P}]$ is not taken to be part of its phonological edge, as it does not have phonological features, contrary to what we find in (3b).

The distinction between (3a) and ( $3 b)$ in terms of (4b) is conceptually costly, though. First, it is at odds with the standard assumption that the computational system only sees formal features. This becomes even more patent if phonological features are to be inserted much later in the derivation, as in the framework of Distributed Morphology (see e.g., [16]). But even under the weak lexicalist view adopted in [9], resort to (4b) may require very global computations, given that the phonetic realization of chains is defined in the phonological component and includes the possibility that traces may be phonetically realized (see e.g., [6,7], and references therein). So, the "phonological edge" of a given structure may not be yet specified at the derivational step where agreement/movement is expected to be blocked.

There is also a cyclicity problem with this analysis of (3a), under the assumption that derivations obey the Extension Condition [5]. Before the subject moves, we have the structure in (5) below, which is for the relevant purposes identical to the one that underlies $(3 b)$. In other words, when the subject moves in (5), it crosses not a trace, but the head of the (partial) wh-chain.

(5) [T [ $v$ P what wbj $\left[\mathrm{Jjohn}_{\text {Subj }}\right.$ read $\left.\left.t_{\mathrm{Obj}}\right]\right]$

Addressing these issues, Chomsky [9] (p. 27) suggests that Agree and Move apply freely in the course of the derivation and that "[ $t$ ]he probe-goal relation must be evaluated for the Minimal Link Condition (MLC) at the strong-phase level after it is known whether the outer edge of $v \mathrm{P}$ has become a trace, losing its phonological features." Although this suggestion captures the wanted contrast between (3a) and (3b), it looks somewhat unattractive as it invokes a representational computation in a model that strives to enforce a derivational approach to syntactic computations.

This discussion indicates that the attempt to eliminate equidistance by trying to subsume (3) under (1) seems to come at too high a price. In this paper I would like to suggest an alternative that keeps equidistance, allowing movement of the subject in (3a), and excludes ( $3 \mathrm{~b}$ ) as a violation of Last Resort, as there is no motivation for the object to undergo movement to [Spec,vP]. The novelty focuses on cases like (1), where equidistance is not at play. Assuming that an element can only move if it benefits from the movement 
(the Greed Principle, see [4]), the most common scenario for a nontrivial chain to arise is sketched in (6), where an element $X$ with an unvalued feature moves to a position where this feature becomes valued.

(6) $\quad\left[X_{\sqrt{ }[\mathrm{F}: v a l]} \ldots \mathrm{X}_{[\mathrm{F}: \mathrm{u}]} \ldots\right]$

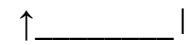

Now suppose that the relevant distinction in (1) is not between traces and chain heads or whole chains, but between being fully specified and not being fully specified. One may then naturally assume that if a given element has an unvalued feature, it is not fully specified and as such, does not qualify as a proper intervener for purposes of minimality computations. In the derivational step in (7a) below, for instance, $\mathrm{Y}$ can cross $\mathrm{X}$ even if they are of the same type, because $X$ is not sufficiently specified to count as a proper intervener; in $(7 \mathrm{~b})$, on the other hand, the relevant feature of the upper instance of $X$ is valued and induces a minimality violation, for $X$ has now become a fully specified element.

(7) $\quad$ a. $\left[Y_{\mathrm{k}} \ldots \mathrm{X}_{[\mathrm{F}: \mathrm{u}]} \ldots t_{\mathrm{k}} \ldots\right]$

b. ${ }^{*}\left[Y_{k} \ldots X_{\sqrt{ }[F: v a l]} \ldots X_{[F: u]} \ldots t_{k} \ldots\right]$

Bearing this in mind, let us reconsider the contrast in (1). Quirky Case is standardly assumed to require licensing by a structural Case checker/assigner, which amounts to saying that in the concrete case of $(1 a) /(2 a)$ and $(1 b) /(2 b)$, the matrix experiencer enters the derivation with an unvalued feature that gets valued/licensed when the experiencer moves to [Spec,TP]. Thus, the copy left behind does not block an agreement relation across it because it is not a fully specified syntactic object (not all of its features are valued). The matrix $T$ can then successfully agree with the embedded nominative in (1a)/(2a), as sketched in (8a) below, but not in $(1 b) /(2 b)$, as sketched in $(8 b)$. The problem with $(8 b)$ is not the lower copy of the matrix experiencer or the lower copy of the embedded quirky subject, but the upper copy of the embedded subject, which is fully specified. As for (1c)/(2c), we may consider two scenarios. If the experiencer is fully specified, as sketched in (8c), it blocks movement of the embedded subject. On the other hand, if it is not fully specified, as represented in $\left(8 c^{\prime}\right)$, it does not block movement of the embedded subject but if the embedded subject moves to the matrix [Spec,TP], the experiencer will not be licensed. In either scenario, the derivation crashes.

(8) a. [TP me $\sqrt{[F: v a l]}[\mathrm{T}[v \mathrm{P}$ me[F:u] thought [they be industrious]]]

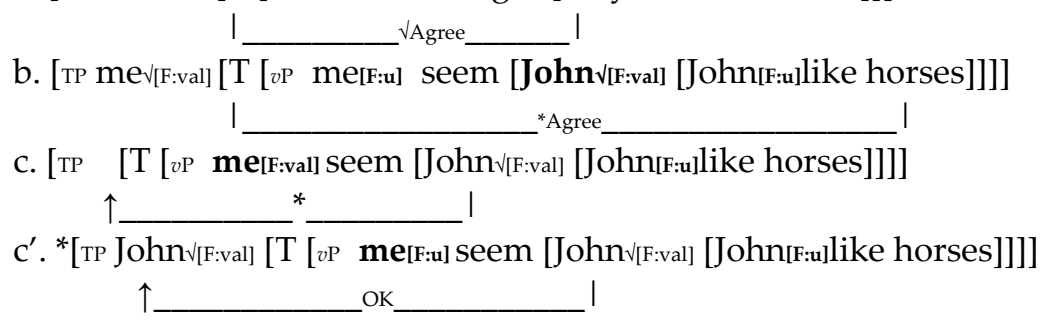

At face value, it seems that this proposal is just a notational variant of the original proposal in [8], presented from a different conceptual angle. Indeed, both proposals make the same predictions when we are dealing with unvalued uninterpretable features. However, as argued in [17], among others, the relation between interpretability and valuation is not biconditional and we also find cases of valued uninterpretable features (which must still be checked against matching interpretable features in order to be licensed). Interestingly, the two proposals differ in their predictions when valued uninterpretable features are involved. Take, for instance, the derivational step in (9) below, where $X$ and $Y$ are of the same type for purposes of minimality computations and $X$ has a valued uninterpretable feature. From the perspective of [8], Y can move across X at the step sketched in (9) if X moves before the phase is ready for Transfer, as illustrated in (10a), because at the phase level, $Y$ will have crossed just a trace of $X$, but not the head of the chain or the whole chain. Under the current proposal, on the other hand, movement of $Y$ simply cannot cross $X$ in (9), as sketched in 
(10b), because $X$ is fully specified. Moreover, eventual additional movements of $X$ later in the derivation do not void the violation in (10b), for the copy left behind in (10b) will still be fully specified.

(9) $\left[\ldots X_{[\mathrm{F}: \mathrm{val}]} \ldots \mathrm{Y} \ldots\right]$

(10) a. Derivation under [8]:

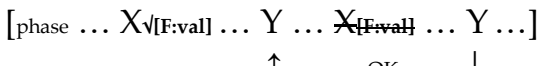

b. Derivation under current proposal:

$\left[\mathrm{Y} \ldots \mathrm{X}_{[\mathrm{F}: \mathrm{val}} \ldots \mathrm{Y} \ldots\right]$

Extending the proposals in [12,18], I argue below that much of the crosslinguistic variation involved in multiple wh-questions revolves around moving across wh-traces fully specified, as in (10b), or not fully specified, as in (7a). But before we discuss multiple wh-questions with respect to the proposal above, we will first briefly examine the account of successive cyclic wh-movement in [11], which will lay out the basis for our analysis of minimality effects or lack thereof involving movement across traces.

\section{Edge Features and wh-Movement}

Although there is a consensus that the final step of a wh-movement operation should involve an agreement relation between the interrogative complementizer $(\mathrm{Q})$ and the moved wh-element, things are not clear with respect to the preceding intermediate cyclic steps. Under the assumption that such movements, like other syntactic movements, should be feature-driven, there should be features triggering successive cyclic movement. Addressing this issue, Chomsky [8] proposes that after a given phase is completed, its head may be optionally assigned an EPP-type of feature, attracting a wh-phrase to its Spec. If the phase heads intervening between the base-generation site and the final agreement site are all assigned this $\mathrm{A}^{\prime}$-EPP feature, as sketched in (11), wh-movement proceeds in a successive cyclic moment, in compliance with the Phase Impenetrability Condition, as desired.

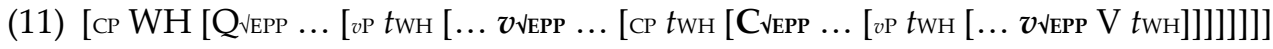

The assignment of the $\mathrm{A}^{\prime}$-EPP feature to phase heads must be optional for two reasons. First, phase heads should not be obligatorily associated with the A'-EPP feature, for otherwise simple declarative sentences with no $\mathrm{A}^{\prime}$-movement would always crash, because the $\mathrm{A}^{\prime}$-EPP would remain unchecked. And second, even a language such as English, which has obligatory movement in simple wh-questions (putting aside quiz- and echo-questions), has wh-in situ in multiple wh-questions. Under this approach, the convergent derivation of (12) below, for instance, requires that the embedded $v$ not be assigned the A'-EPP feature. Notice that the ungrammaticality of (13a) as a standard request for information can be accounted for if the interrogative complementizer has an uninterpretable wh-feature. If $v$ is not assigned the $\mathrm{A}^{\prime}$-EPP feature, what does not move and Q cannot check its wh-feature against what, due to the Phase Impenetrability Condition.

(12) Who said that John bought what?

(13) a. ${ }^{*}$ Did you buy what?

b. [cР did-Q[wh] [you [vp $v$ buy what]]]

I__PIC

Despite being able to enforce successive cyclic movement in the system by encoding optionality on phase heads, the proposal in [8] overgenerates, as convincingly argued by Bošković [12]. If the embedded $v$ in (12) were assigned the A'-EPP feature, for instance, the sentence in (14) would be incorrectly ruled in and its exclusion would need look-ahead and global computations.

(14) *Who said that John what bought? 
The alternative proposed by Bošković [12] is to encode optionality on the wh-elements themselves, subject to crosslinguistic variation. The movement-triggering feature, which he refers to as $u F$, would be obligatory on wh-elements in multiple wh-fronting languages like Bulgarian, inexistent on wh-elements of wh-in situ languages like Korean, and optional on wh-elements of languages like English. Crucially, a sentence such as (14) is excluded with no look-ahead. If what has moved, it must be the case that it bears uF; but if so, the derivation of (14) crashes as soon as the constituent containing what undergoes Transfer, for $\mathrm{uF}$ will not have been checked by the appropriate head.

Although it provides an elegant solution to the overgeneration problem in [8], Bošković's proposal [12] is forced to require additional provisos to account for the fact that languages may display subject-object asymmetries. As is well known, in English an embedded wh-object can cross a local overt complementizer, but an embedded wh-subject cannot (see (15) below). The problem with (15) under [12] is that in order to move, the wh-phrases must be endowed with $\mathrm{uF}$, but if this is so, the type of complementizer on their way should not matter. In fact, the only problematic complementizer is the one that is local to the subject extraction site. As shown in (16), a higher overt complementizer does not interfere with subject extraction. Interestingly, Bošković's proposal for English [12] seems more congenial to wh-movement in Brazilian Portuguese. As shown by the pairs (17a) and (17a'), on the one hand, and $(17 \mathrm{~b})$ and $\left(17 b^{\prime}\right)$, on the other, wh-movement in Brazilian Portuguese is optional and there is no subject-object asymmetry. The optionality is even clearer than the English case, for in situ wh-phrases in Brazilian Portuguese are allowed in single wh-questions (see (17a) and (17b)), which indicates that its interrogative complementizer does not have an uninterpretable wh-feature.

(15) a. What did you say (that) John bought?

b. Who did you say (*that) bought a house?

(16) Who did you say (that) John thinks (*that) bought a house?

(17) Brazilian Portuguese:

a. Você acha que quem vai ganhar a eleição?

you think that who goes win the election

a'. Quem você acha que vai ganhar a eleição?

who you think that goes win the election

'Who do you think is going to win the election?'

b. Você acha que o João vai comprar o quê?

you think that the João goes buy what

$b^{\prime}$. O que você acha que o João vai comprar?

what you think that the João goes buy

'What do you think that João is going to buy?'

If Brazilian Portuguese is actually the language that better fits Bošković's description of a language whose wh-phrases are optionally specified for $\mathrm{uF}$, the question is how to analyze English-type languages, which exhibit subject-object asymmetries with respect to whextraction. Nunes [11] proposes that the feature that triggers successive cyclic movement, which he refers to as an edge feature $(E F)$, may be lexically associated with wh-elements, as in [12], or with phase heads (or heads of the extended projections of phases), as in [8]. If the phase head is so specified, it assigns EF to the closest wh-element in its probe domain. In the specific case of English, Nunes [11] proposes that its EFs are optionally associated with phase heads, which are then assigned to wh-elements in the course of the derivation.

This proposal inherits the positive aspects of $[8,12]$, while avoiding their intrinsic problems. Like in [8], the optional lexical specification on phase heads allows simple declarative sentences to be derived and converge when the selected phase heads are not associated with EF. Sentences like (13a) are also correctly ruled out: if $v$ is not associated with EF, the object will not receive its EF-fuel and won't be able to move and check the uninterpretable feature of the interrogative complementizer. Like in [12], an unchecked EF causes the derivation to crash when the constituent containing it undergoes Transfer. 
The derivation of (14), for example, is ruled out based on local computations. What in (14) can only move if it has been assigned EF by the embedded $v$, but if this is the case, it cannot stop in the embedded [Spec, $v \mathrm{P}$ ], for EF is not licensed in this position and will cause the derivation to crash when the embedded TP undergoes Transfer. The distinctive property of the proposal in [11] is that subject-object asymmetries may arise if different phase heads may have different specifications with respect to EF. In the case of English, for instance, Nunes argues that $v$ and the null declarative $C$ are optionally specified for EF, but declarative that is not specified for EF. This means that in a configuration like (18a) or (19a) below, the wh-element can undergo movement because it may be assigned EF by $v$ or the null complementizer $C_{\varnothing}$, but the $w h$-subject in (20a) cannot, because that is not specified for EF. Hence, object extraction in English is oblivious to the complementizers it crosses (see (15a)), whereas subject extraction is sensitive to the specific local complementizer it is in the domain of (see (15b)).

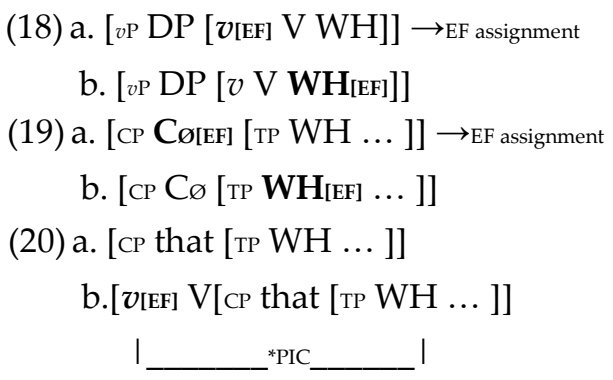

Notice that if a wh-subject receives EF from a null complementizer as in (19b), it behaves like an object in being oblivious to a higher complementizer. In (16), for instance, the wh-subject can cross the complementizer that in the intermediate clause because it already has its fuel for the ride (the edge feature it got from the null complementizer). On the other hand, the wh-subject in (20a) cannot move even if the $\mathrm{CP}$ is embedded within a $v \mathrm{P}$ phase with an EF-bearing $v$, as sketched in (20b), for the Phase Impenetrability Condition prevents $v$ from assigning $\mathrm{EF}$ to $\mathrm{WH}$.

In sum, whether EFs are lexically hosted by wh-elements or phase heads may have different consequences for $w h$-movement. We will see in the next section, that it may also affect minimality computations of the sort outlined in Section 2.

\section{Moving across Copies with Valued and Unvalued Edge Features}

As discussed above, the role of EFs is to make it possible for two elements located in different phasal spans to interact in compliance with the Phase Impenetrability Condition, by (repeatedly) dislocating the lower element to a phase edge, yielding successive cyclic movement. It is thus clear that although the relevant relation or configuration made available by an edge feature may be assigned a special interpretation, EFs are just the go-betweens and are not by themselves interpretable. That being the case, there arises the issue of EFs' intrinsic value. As argued by Pesetsky and Torrego [17], among others, the relation between interpretability and intrinsic value is not biconditional and uninterpretable features may be unvalued (the unmarked case) or valued (the marked case). So, the question before us is whether EFs are uniformly valued or unvalued across languages or whether their value is subject to crosslinguistic variation, with the additional possibility that the value of EFs may vary within the same language depending on their specific lexical hosts.

At first sight, it does not seem possible to distinguish among these possibilities, for EFs must move to a position where they can be licensed, regardless of whether they are intrinsically valued or unvalued. However, if we assume the proposal made in Section 2 relating the transparency or opaqueness of copies to their being partially or fully specified, we make very specific predictions that may shed light on this question. In particular, we make the prediction that a copy bearing an unvalued instance of EF should count as transparent for movement across it, but a copy bearing a valued instance of EF should block movement across it. In order to test this, we have to further ensure that the relevant 
test cases involve a moved element of the same type as the crossed element, so that (some version of) Relativized Minimality [19] is complied with. Given this general setting, multiple wh-questions constitute a natural terrain for us to probe into the intrinsic value of EFs (see [18] for detailed discussion).

Let us then begin exploring the connection between valuation and transparency made in Section 2, by considering the three logical possibilities sketched in (21).

(21) a. [Q ... WH1 ... WH $\left.\mathrm{WH}_{2} \ldots\right]$

b. $\left[\mathrm{Q} \ldots \mathrm{WH}_{1[\mathrm{EF}: \mathrm{Q}]} \ldots \mathrm{WH}_{2[\mathrm{EF}: \mathrm{Q}]} \ldots\right]$

c. $\left[\mathrm{Q} \ldots \mathrm{WH}_{1[\mathrm{EF}: \mathrm{u}]} \ldots \mathrm{WH}_{2[\mathrm{EF}: \mathrm{u}]} \ldots ..\right]$

In the three structures of (21), the interrogative complementizer $Q$ does not have a wh-feature. This amounts to saying that if wh-movement takes place, the motivation should be found on the wh-elements, rather than Q. In (21a) the wh-elements are not specified for EF; hence, no wh-movement should be triggered. (21a) can thus be taken to be the general description of the typological possibility represented by languages like Chinese, which allows multiple wh-questions and all wh-phrases surface in situ, as illustrated in (22).

(22) Chinese [20]:

$\mathrm{Ni}$ xiang-zhidao Lisi weisheme mai-le sheme?

you wonder Lisi why bought what

'What do you wonder why Lisi bought (it)?'

(21b) illustrates a more interesting case. The wh-elements are specified for a valued instance of EF. This means that they both have to undergo movement to [Spec,CP] to check EF against Q. Given that EFs in both wh-phrases are valued, the prediction is that except for the cases allowed due to equidistance, one wh-element should not be able to cross the other. For the sake of illustration, consider the abstract derivation of a sentence in which $\mathrm{WH}_{1}$ in (21b) corresponds to the external argument and $\mathrm{WH}_{2}$, to an internal argument, as depicted in (23):

(23) a. [vP $\left.\mathrm{WH}_{1[\mathrm{EF}: \mathrm{Q}]}\left[v^{\prime} v\left[\mathrm{VP} \mathrm{V} \mathrm{WH}_{2[\mathrm{EF}: \mathrm{Q}]}\right]\right]\right]$

b. [vP WH $\left.2[\mathrm{EF}: \mathrm{Q}]\left[v^{\prime} \mathrm{WH}_{1[\mathrm{EF}: \mathrm{Q}]}\left[v\left[\mathrm{VP} \mathrm{V} \mathrm{WH}_{2[\mathrm{EF}: \mathrm{Q}]}\right]\right]\right]\right]$

$\uparrow \_$OK (equidistance)

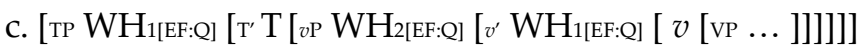

$\uparrow \_$OK (equidistance) ___

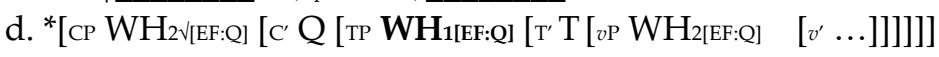

$\uparrow \ldots$ (intervention) _

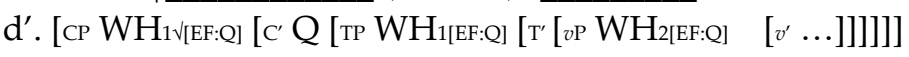

$\uparrow \ldots$

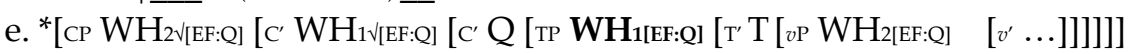

* (intervention)

In accordance with definition of equidistance in [5], movement of $\mathrm{WH}_{2}$ to the outer [Spec, $v \mathrm{P}]$ in $(23 \mathrm{~b})$ is not blocked by $\mathrm{WH}_{1}$ because the moved copy of $\mathrm{WH}_{2}$ falls within the same minimal domain as $\mathrm{WH}_{1}$ (they are dominated by the same maximal projections). For the same reason, $\mathrm{WH}_{2}$ does not block movement of $\mathrm{WH}_{1}$ to $[\mathrm{Spec}, \mathrm{TP}]$ in (23c). Now, it is time for the wh-elements to move to check their EFs. Given that the copy of $\mathrm{WH}_{1}$ in [Spec,TP] is fully specified (it got its Case feature valued and its EF is intrinsically valued), it prevents movement of $\mathrm{WH}_{2}$ across it, as shown in (23d). As an alternative derivational step, $\mathrm{WH}_{1}$ can move to [Spec,CP] and have EF licensed, as shown in (23d'). The next step is the crucial one, as it teases apart the proposal in [8] that traces do not induce intervention effects from our proposal that only copies that are not fully specified are transparent with respect to minimality computations, as sketched in (10), repeated below in (24) for convenience. 
(24) a. Derivation under [8]:

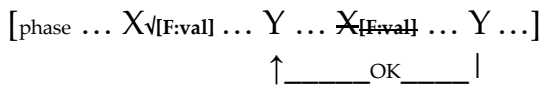

b. Derivation under current proposal:

$[\mathrm{Y} \ldots \mathrm{X}$ [F:val] ... Y ...]

The prediction of [8] with respect to the derivation outlined in (23) is that the derivation should converge if it proceeds along the lines of $\left(23 \mathrm{~d}^{\prime}-\mathrm{e}\right)$, for $\mathrm{WH}_{1}$ in $[\mathrm{Spec}, \mathrm{TP}]$, as a trace, would be unable to block movement of $\mathrm{WH}_{2}$. Put in general terms and leaving equidistance aside, superiority violations should always be circumvented if there is a derivational route in which only wh-traces are crossed. From the perspective of our proposal, on the other hand, if $\mathrm{EF}$ on $\mathrm{WH}_{1}$ is valued, the derivation should crash even under the derivation steps in $\left(23 d^{\prime}-e\right)$, for the copy left behind by the movement of $\mathrm{WH}_{1}$ to [Spec,CP] still counts as a proper intervener for the movement of $\mathrm{WH}_{2}$. To put in general terms, if the wh-elements of a given language $\mathrm{L}$ are obligatorily associated with a valued instance of EF, L does not allow multiple wh-questions. This typological possibility predicted by our account is instantiated by languages like Irish, for example, which does not allow multiple wh-questions even if the order of the wh-phrases is consistent with superiority, as shown in (25).

(25) Irish [21]:

${ }^{*}$ Cé aL rinne caidé?

who C did what

'Who did what?'

The current proposal also derives Stoyanova's generalization [22], according to which languages that do not allow multiple wh-questions (Irish, Italian, Berber, and Somali, for instance) do not allow wh-in situ either. If the prohibition of multiple wh-questions in a language is due to its wh-elements being obligatorily specified for a valued instance of EF (which entails minimality violations when one wh-element crosses the other), an in situ wh-phrase causes the derivation to crash because its EF feature is not licensed.

The reasoning developed above also makes room for the typological possibility predicted in (21c), namely, languages whose wh-elements are obligatorily associated with an unvalued instance of EF. Such languages should require multiple wh-fronting, in virtue of the obligatory presence of EF on their wh-phrases, but should not display superiority effects if the crossed wh-elements still have their EFs unvalued. A derivation analogous to (23), for example, may take two derivational routes and each of them converges. That is, after the derivation reaches the stage in (26c) below, it may proceed as in (27) or (28).

(26) a. [vP $\left.\mathrm{WH}_{1[\mathrm{EF}: \mathrm{u}]}\left[v^{\prime} v\left[\mathrm{VP} \mathrm{V} \mathrm{WH}_{2[\mathrm{EF}: \mathrm{u}]}\right]\right]\right]$

b. [vP WH2[EF:u] [v' $\mathrm{WH}_{1[\mathrm{EF}: \mathrm{u}]}\left[v\right.$ [vP $\left.\left.\left.\left.\mathrm{VWH}_{2[\mathrm{EF}: \mathrm{u}]}\right]\right]\right]\right]$

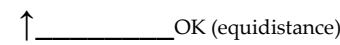

c. [TP $\left.\mathrm{WH}_{1[\mathrm{EF}: \mathrm{u}]}\left[\mathrm{T}^{\prime} \mathrm{T}\left[v \mathrm{P} \mathrm{WH}_{2[\mathrm{EF}: \mathrm{u}]}\left[v^{\prime} \mathrm{WH}_{1[\mathrm{EF}: \mathrm{u}]}[v[\mathrm{vP} \ldots]]\right]\right]\right]\right]$ OK (equidistance)
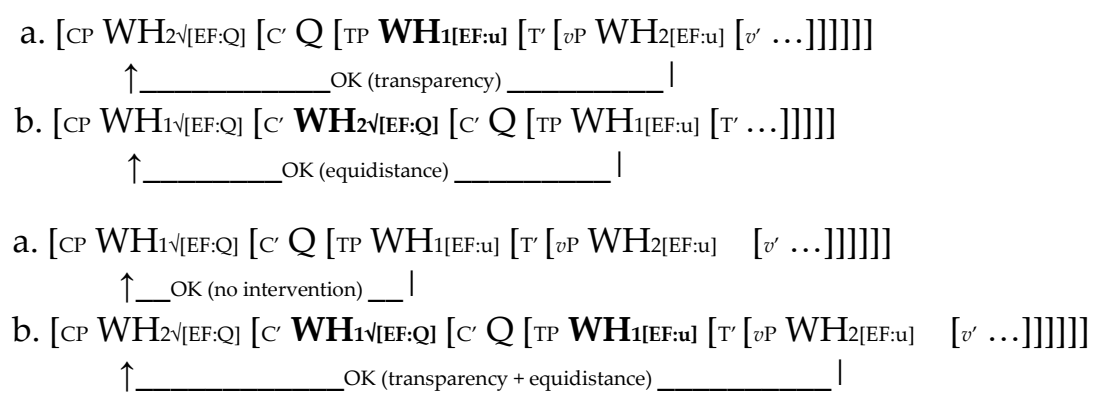

In (27a), the unvalued instance of $\mathrm{WH}_{1}$ makes it transparent with respect to the movement of $\mathrm{WH}_{2}$; the valued feature of $\mathrm{WH}_{2}$ in $(27 \mathrm{~b})$ could then make it count as a proper intervener, but the subsequent movement of $\mathrm{WH}_{1}$ lands in the minimal domain where $\mathrm{WH}_{2}$ is located, which is allowed by equidistance. So, the derivation converges with $\mathrm{WH}_{1}$ 
preceding $\mathrm{WH}_{2}$. In (28b), on the other hand, $\mathrm{WH}_{2}$ crosses two copies of $\mathrm{WH}_{1}$ without yielding a minimality/superiority effect because the lower copy is transparent due to its unvalued $\mathrm{EF}$ and the upper copy is in the same minimal domain as the moved $\mathrm{WH}_{2}$. The derivation then converges with $\mathrm{WH}_{2}$ preceding $\mathrm{WH}_{1}$. Multiple $w h$-fronting constructions with no superiority effects, like the Serbo-Croatian data in (29) below, respectively exemplify the derivations outlined in (27) and (28).

(29) Serbo-Croation [23]:

a. Ko koga voli who whom loves

b. Koga ko voli whom who loves 'Who loves who?'

Let us now consider languages like Brazilian Portuguese, whose wh-elements are optionally associated with EF (see Section 3). The question is whether EFs in Brazilian Portuguese are intrinsically valued or unvalued. Take the data in (30) below, for instance.

(30) BrazilianPortuguese [18]:

a. Você acha que quem comprou o quê? you think that who bought what

b. Quem você acha que comprou o quê? who you think that bought what

c. * Quem o que você acha que comprou? who what you think that bought

d. ${ }^{*}$ O que quem você acha que comprou? what who you think that bought

e. *O que você acha que quem comprou? what you think that who bought 'Who do you think bought what?'

(30a) and (30b) are not informative. (30a) shows a case in which neither wh-element exercised its option of being associated with EF and in (30b) only the higher wh-element (quem 'who') moves and it could thus be associated with a valued or an unvalued instance of EF. The fact that (30c) and (30d), with multiple $w h$-fronting, are ungrammatical regardless of the order of the wh-elements, suggests that EF is not unvalued. That being so, quem in (30b) and o que 'what' in (30e) are associated with an instance of EF intrinsically valued. Movement of quem in (30b) to license its EF does not find any proper intervener on its way to [Spec, CP], but movement of o que in (30e) does. Crucially, although quem in (30e) is not associated with EF (hence, it does not undergo wh-movement), the copy in the embedded [Spec,TP] becomes fully specified when its Case feature gets valued, blocking movement of o que (a standard superiority effect).

English differs from Brazilian Portuguese in two orthogonal ways. First, its interrogative complementizer has an uninterpretable wh-feature (see (13b)), which rules out sentences analogous to (30a), with no wh-movement, as exemplified in (31a) below. Second, EFs are lexically associated with phase heads, which may induce a subject-object asymmetry with respect to wh-extraction (see (15)). Once the independent subject-object asymmetry is controlled for by using an embedded null complementizer, English behaves just like Brazilian Portuguese with respect to multiple wh-questions, as shown in (31b-e). We may thus conclude that $v$ and declarative $C_{\varnothing}$ in English may be optionally associated with a valued instance of EF. Of course, these are lexical specifications, which are independent from each other. In (31b), for instance, the embedded $C_{\varnothing}$ is associated with EF, but the embedded $v$ isn't, whereas in (31e), the opposite situation holds. Thus, in (31b), the embedded wh-subject undergoes movement after being assigned EF by the null complementizer (see (19)) and the same happens with what in (31e) after it receives EF from $v$ (see (18)). Wh-movement leads to a convergent result in (31b), but not in (31e) due to the intervention of who. Exactly like we saw in Brazilian Portuguese with respect to quem in (30e), who in (31e) does not have EF, but gets fully specified after it has its Case valued. 
(31) a. *Do you think who bought what?

b. Who do you think bought what?

c. *Who what do you think bought?

d. *What who do you think bought?

e. *What do you who think bought?

Observe an interesting feature of the present proposal, as compared to [12]. Bošković's proposal [12] straightforwardly distinguishes multiple $w h$-fronting languages (languages with wh-elements obligatorily specified for $\mathrm{uF}$ in his system) from languages with no wh-movement in multiple wh-questions (languages with $w h$-elements obligatorily specified for $i F-$ an interpretable version of $F$ in his system). As for languages like English where only one $w h$-phrase undergoes movement in multiple wh-questions, the proposal that their wh-phrases are optionally specified for $\mathrm{uF}$ needs to be supplemented with the assumption that their complementizers do not allow multiple specifiers [12] (p. 75). Otherwise, English sentences with multiple wh-fronting to [Spec,CP] such as (32) below (or (30c,d)), for instance, would be incorrectly ruled in if both $w h$-elements exercised their option of being specified with uF. Although not discussed by Bošković, this putative ban on multiple specifiers in some languages could also be employed to account for languages like Irish, which lack multiple wh-constructions (see (25)).

(32) *Who what bought?

The problem with the account of this crosslinguistic difference in terms of whether complementizers allow one or more specifiers in a given language is that it is not at all trivial how to state this constraint under bare phrase structure, for specifier is a derived relational notion. Under the present proposal, by contrast, there is no stipulation regarding the number of specifiers a given head may take. An interrogative complementizer $Q$, for instance, may in principle take any number of specifiers. It just happens that if more than one wh-element bears $\mathrm{EF}$ and needs to move and land in a specifier of $C$, minimality must be observed. This in turn entails that languages may differ as whether $\mathrm{EF}$ is intrinsically valued or not. If it is unvalued, multiple $w h$-fronting may take place, yielding a multiple specifier structure, because the potential interveners are transparent in virtue of not being fully specified (see (27)). If EF is intrinsically valued, it will induce minimality/superiority effects and yield a single specifier structure. Whether a "single specifier" language (i.e., a language with intrinsically valued EFs) allows multiple wh-questions or not will depend if EFs are optionally or obligatorily associated with their lexical hosts. If they are optional, multiple wh-questions with a single superiority-complying wh-movement are allowed (Brazilian Portuguese and English, for instance); if they are obligatory, multiple wh-questions are ruled out by minimality (Irish and Italian, for instance). To put this in more general terms, the independently required lexical specification and intrinsic value of EFs pave the way to a deduction of the crosslinguistic variation regarding the number of specifiers $C$ may license (see [11] for further discussion).

This reasoning seems to face an insurmountable problem, though. It seems to make an indissoluble correlation between multiple $w h$-fronting and lack of superiority effects. However, the seminal work on multiple wh-fronting by Rudin [24] has shown that the two properties do not always go hand in hand. Bulgarian, for instance, has multiple wh-fronting like Serbo-Croatian (see (29)), but displays superiority effects, as illustrated in (33) below.

(33) Bulgarian [24]:

$$
\begin{aligned}
& \text { a. Koj kogo vižda? } \\
& \text { who whom sees } \\
& \text { b. *Kogo koj vižda? } \\
& \text { whom who sees } \\
& \text { 'Who sees whom?' }
\end{aligned}
$$

From the perspective of the present proposal, the existence of languages like Bulgarian is very challenging. If multiple $w h$-fronting is involved, it must be the case that the wh-phrases of the language are obligatorily specified for EF. Moreover, in order for the 
crossing movements to be allowed, it must be the case that the edge features associated with the wh-phrases are intrinsically unvalued so that they become transparent with respect to the other moving wh-phrases (see (27a) and (28b)). But if that is so, why does the final result display a superiority effect? I would like to suggest that Bulgarian is in a sense a mixture between Serbo-Croatian and English. Like Serbo-Croatian, Bulgarian wh-phrases are obligatorily associated with unvalued EFs. Thus, multiple wh-fronting is required as the wh-elements must have their EFs valued. The derivation of the sentences in (33) thus proceeds along the same lines as the derivation of analogous sentences in Serbo-Croatian until TP is built (see (26)), as sketched in (34a) below. Suppose that Bulgarian is also like English in that a valued instance of EF may be lexically hosted by a functional head of the extended projection of CP. More concretely, suppose that the left periphery of an interrogative clause in Bulgarian is split into a Force projection with a $Q$ head and a Focus projection with its head obligatorily specified for a valued instance of EF, as shown in (34b). After (34b) is built, the Focus head assigns EF to the closest wh-element in its probe domain $\left(\mathrm{WH}_{1}\right)$, as shown in $(34 \mathrm{c})$.
a. [тр $\mathrm{WH}_{1[\mathrm{EF}: \mathrm{u}]}\left[\mathrm{T}^{\prime} \mathrm{T}\right.$ [vP $\mathrm{WH}_{2[\mathrm{EF}: \mathrm{u}]}\left[v^{\prime} \mathrm{WH}_{1[\mathrm{EF}: \mathrm{u}]}[v[\mathrm{vP} \ldots\right.$ ]]]]]]

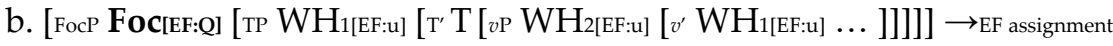

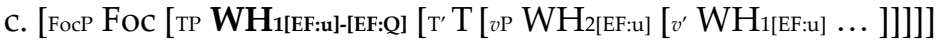

At this point, there are two possible continuations to consider, depending on which $\mathrm{WH}$ moves first. Suppose $\mathrm{WH}_{2}$ moves first, as represented in (35a) below. $\mathrm{WH}_{1}$ does not induce an intervention effect in (35a), due to its original unvalued EF. When $\mathrm{WH}_{2}$ reaches [Spec,FocP], it has its EF feature valued and licensed, for focus is arguably a value compatible with a wh-phrase. Subsequent movement of $\mathrm{WH}_{1}$ in (35b) also values and licenses its unvalued instance of $\mathrm{EF}$, but not the valued instance. $\mathrm{WH}_{1}$ must then proceed to move to [Spec,ForceP], where it licenses its Q-valued instance of EF, as shown in (35c), and the derivation converges.

$$
\begin{aligned}
& \text { a. [FocP WH2v[EF:Foc] [Foc' Foc [TP WH1[EF:u]-[EF:Q] } \left.\left.\quad\left[\mathrm{T}^{\prime} \mathrm{T}\left[v \mathrm{P} \text { WH2[EF:u] }\left[v^{\prime} \ldots\right]\right]\right]\right]\right]
\end{aligned}
$$

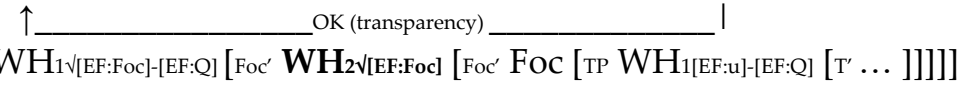





$$
\begin{aligned}
& \uparrow \ldots \text { OK (no intervention) }
\end{aligned}
$$

If $\mathrm{WH}_{1}$ moves first, on the other hand, the derivation unfolds as in (36) below. Movement of $\mathrm{WH}_{1}$ in (36a) values and licenses the unvalued instance of $\mathrm{EF}$, but not the valued instance. $\mathrm{WH}_{2}$ then moves to value its $\mathrm{EF}$, crossing two copies of $\mathrm{WH}_{1}$, but no minimality violation occurs: the lower copy is transparent due to its unvalued EF and the upper copy is within the same minimal domain as the moved copy of $\mathrm{WH}_{2}$. Finally, after Force is merged, $\mathrm{WH}_{1}$ moves and licenses the EF it received from Foc, as shown in (36c).

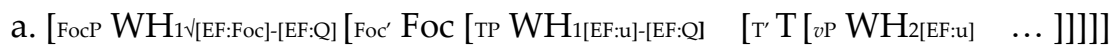

$$
\begin{aligned}
& \uparrow \_ \text {OK (no intervention) }
\end{aligned}
$$

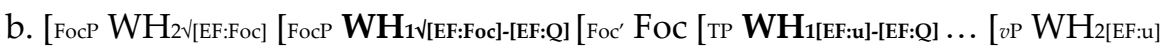

$$
\begin{aligned}
& \mathrm{OK} \text { (transparency + equidistance) } \\
& \text { I }
\end{aligned}
$$



$$
\begin{aligned}
& \text { OK (equidistance) }
\end{aligned}
$$

As the reader can see, regardless of whether the derivation of (34) unfolds along the lines of (35) or (36), the higher phrase $\left(\mathrm{WH}_{1}\right)$ precedes the lower phrase $\left(\mathrm{WH}_{2}\right)$ in the final output, yielding an apparent superiority effect. From the perspective of our proposal, the surface superiority effect illustrated by Bulgarian in (33) is not actually the result from movement violating minimality, but from EF assignment to the most local appropriate target in the probe domain of functional head bearing EF. Crucially, Foc assigns [EF:Q] 
to the higher $\mathrm{WH}$ in (34b-c), which ultimately entails that this wh-element will have to undergo an additional movement, ending up preceding the other $\mathrm{WH}$.

Two pieces of evidence suggest that this analysis is on the right track. From the perspective explored here, Bulgarian is just like Serbo-Croatian, with the addition functional head bearing a valued instance of EF. This makes the prediction that if it were possible to add a head such as Foc ${ }_{[\mathrm{EF}: \mathrm{Q}]}$ to Serbo-Croatian, the result should be as in Bulgarian, with superiority effects. This discussion may allow us to make sense of Bošković's observation [23] that if multiple wh-questions in Serbo-Croatian involve the complementizer-like element $l i$, as illustrated in (38) below, superiority effects arise, in clear contrast with pairs like (29), repeated here in (37).

(37) Serbo-Croatian [23]:

a. Ko koga voli

who whom loves

b. Koga ko voli whom who loves

'Who loves who?'

(38) Serbo-Croatian [23]:
a. Ko li koga voli
who $\mathrm{C}$ whom loves
b. *Koga li ko voli
whom $\mathrm{C}$ who loves
'Who on earth loves whom?'

The surface superiority induced by the presence of $l i$ in (38) suggests that it should be subsumed under the same analysis applied to the Bulgarian data in (34). Concretely, it suggests that the left periphery of interrogative clauses in Serbo-Croatian may be organized in two forms: either we have a syncretic Force/Foc head or a Force head dissociated from a Foc head associated with [EF:Q]. Under the former possibility, the derivations of (37a) and (37b) proceed along the lines of (27) and (28), respectively. Under the latter possibility, (38a) can be derived along the lines of $(34) /(35)$ or $(34) /(36)$ and there is no grammatical source for the derivation of (38b). The order between $l i$ and the wh-elements in (38a) indicates that $l i$ is the Force head rather than the Focus head in the split left periphery version (see [18] for additional reasons based on anti-locality).

The second piece of evidence for the approach to Bulgarian explored here is that it makes it possible to accommodate another typological possibility, namely, the one illustrated by German. As is well known, German patterns like English in not allowing multiple wh-fronting in multiple $w$ h-questions, but differs in not displaying superiority effects, as illustrated in (39) below.

(39) German [25]:

a. Wer hat was gesehen?

who has what bought

b. Was hat wer gesehen?

what has who seen

'Who saw what?'

The fact that German allows multiple wh-questions tells us that its wh-elements are not lexically associated with a valued instance of EF; otherwise, movement of one wh-phrase to [Spec, CP] crossing another wh-phrase or its trace should induce minimality violations. In turn, the fact that in multiple wh-questions only one wh-phrase must be fronted indicates that $w h$-elements in German are not lexically associated with an unvalued instance of EF (otherwise, multiple $w h$-fronting should be enforced) and that its interrogative complementizer is like English in having an uninterpretable wh-feature (precluding generalized wh-in situ). So, the interim conclusion is that German should be analyzed like English in the sense that its phase heads may optionally bear EF and if they do, they assign it to the closest $w h$-phrase in their domain. 
We have seen that lack of superiority effects correlates with an unvalued instance of EF. So, at first sight the relevant difference between English and German can be captured by simply saying that a phase head in English assigns [EF:Q] to the closest wh-element in its domain (giving rise to superiority effects), whereas the German counterpart assigns [EF:u] (voiding superiority). However, this possibility leads to overgeneration problems similar to the ones discussed in Section 3 with respect to (14), under the optional EPP approach [8]. Given that the lexical specification for EF on a given phase head is independent from the lexical specifications on other phase heads, nothing prevents a situation in which more than one phase head is specified for [EF:u] and assigns it to a wh-phrase. If this happens, superiority will indeed be circumvented, but the presence of more than one wh-phrase with [EF:u] should then trigger multiple wh-fronting, yielding an incorrect result for German.

So, we are led to the conclusion that phase heads in German are similar to their English counterparts in assigning a valued instance of EF, which leaves the lack of superiority effects illustrated in (39) as a mystery. Our analysis of Bulgarian (and Serbo-Croatian multiple wh-questions with $l i$ in (38)) seems to have the right ingredients to get us out of this puzzle, though. Recall that what gave rise to apparent superiority effects in Bulgarian was the introduction of a functional head in the left periphery of the interrogative clause with a marked specification for EF. In the case of Bulgarian, whose wh-phrases are specified for an unvalued instance of EF, this marked specification corresponds to a valued instance of EF. Let us then suppose that that German is like Bulgarian in having a functional head above TP with a marked specification for EF, which in the case of German corresponds to an unvalued instance of EF. Under this hypothesis, the simplified derivation of a sentence such as (39b), for instance, proceeds along the lines of (40) and (41):

$$
\begin{aligned}
& \text { a. [vP } \left.\mathrm{WH}_{1}\left[v_{\text {[EF:Q] }} \mathrm{WH}_{2} \mathrm{~V}\right]\right] \rightarrow \mathrm{EF} \text { assignment } \\
& \text { b. [vP WH} 1 ~\left[v \mathbf{W H}_{2[\mathrm{EF}: \mathrm{Q}] \mathrm{V}]]}\right. \\
& \text { c. [vP WH} \left.2[\mathrm{EF}: \mathrm{Q}]\left[v^{\prime} \mathbf{W H}_{1}\left[v \mathrm{WH}_{2[\mathrm{EF}: \mathrm{Q}]} \mathrm{V}\right]\right]\right] \\
& \uparrow \_ \text {OK (equidistance) ___ }
\end{aligned}
$$

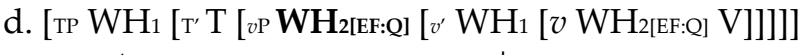

$$
\begin{aligned}
& \uparrow \_ \text {OK (equidistance) }
\end{aligned}
$$

(41) a. [Fе $\mathbf{F}[\mathrm{EF}: \mathrm{u}]\left[\mathrm{TP} \mathrm{WH}_{1}\left[\mathrm{~T}^{\prime} \mathrm{T}\left[\mathrm{vP} \mathrm{WH}_{2[\mathrm{EF}: \mathrm{Q}]}\left[v^{\prime} \ldots\right.\right.\right.\right.$ ] $\left.\left.\left.]\right]\right]\right] \rightarrow$ EF assignment

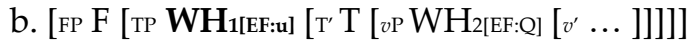



OK (transparency)

In (40a), $v$ has exercised its option of bearing EF and assigns it to the (vacuously closer) wh-element in its probe domain (see (40b)). $\mathrm{WH}_{2}$ then moves to the edge of $v \mathrm{P}$ (see (40c)), followed by movement of the external argument to [Spec,TP]. In English, a derivation along the lines of (40) is doomed to crash (see (31e)), for $\mathrm{WH}_{1}$ becomes fully specified after having its Case valued and blocks the required movement of $\mathrm{WH}_{2}$ to license its EF. In German, on the other hand, the partial derivation sketched in (40) need not meet the same fate if it unfolds as in (41), with the merger of a functional head F bearing an unvalued instance of EF. After $\mathrm{WH}_{1}$ is assigned [EF:u], as shown in (41b), it becomes transparent in virtue of its newly acquired unvalued feature and does not block movement of the lower wh-element across it, as sketched in (41c).

As is, (41c) is not convergent yet because of the unvalued instance of EF on $\mathrm{WH}_{1}$. In principle, $\mathrm{WH}_{1}$ in (41c) could license EF by moving to the outer [Spec, $\mathrm{CP}$ ] in consonance with equidistance. Alternatively, $\mathrm{WH}_{1}$ could also have moved to [Spec,CP] before movement of $\mathrm{WH}_{2}$, yielding a convergent output, for the copy of $\mathrm{WH}_{1}$ in [Spec,TP] would be transparent for movement of $\mathrm{WH}_{2}$ and the two specifiers of $\mathrm{CP}$ would be equidistant. Despite being convergent, these two derivations are ruled out by economy considerations, under the assumption that movement is a last resort operation. $\mathrm{WH}_{1}$ in (41c) can license EF in a more economical way by probing the structure and valuing EF via agreement with the valued instance EF on the lower copy of $\mathrm{WH}_{2}$, as illustrated in (42) below (see [26] for further discussion). 
(42)

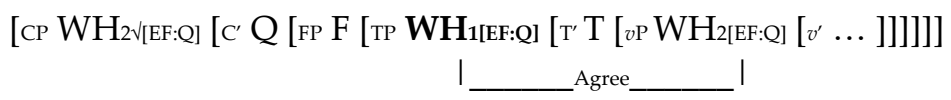

Notice that if $\mathrm{WH}_{1}$ had agreed with $\mathrm{WH}_{2}$ at the derivational step in (41b), it would have become fully specified, blocking the movement of $\mathrm{WH}_{2}$. So, the most economical (convergent) continuation after $\mathrm{F}$ is merged in (41a) is the one where $\mathrm{WH}_{1}$ agrees with the lower copy of $\mathrm{WH}_{2}$ after the latter moves, as depicted in (42). Moreover, observe that this reasoning is in perfect consonance with the strictly derivational nature of phase-based computations: the output in (42) can be obtained in a derivational fashion, with each derivational step complying with minimality, despite the fact that the final representation contains a different $w$ h-element intervening between the links of the chain involving $\mathrm{WH}_{2}$.

To summarize, assignment of a valued instance of EF may enforce superiority in multiple wh-fronting languages and assignment of an unvalued instance of EF may void superiority effects in languages that allow multiple $w$ h-questions, but not multiple $w h$-fronting. Bulgarian (see (33)) and, in a more restrictive way, Serbo-Croatian (see (38)) illustrate the first case and German seems to fit the profile of the second case. I leave to another occasion an adequate discussion of which head of the left periphery of German F in (41a) corresponds to.

\section{Concluding Remarks}

Let us take stock. Chomsky [8] has proposed that lower copies do not block movement across them. Under the copy theory, this theoretical description, even if empirically motivated, requires further elaboration. If distinctions making reference to the highest copy of a given chain in opposition to lower copies are not independently justified, we face the risk of reintroducing traces as theoretical primitives. In this paper I have argued that the justification for the usual transparency of lower copies is that in general, they do not have all of their features valued. This makes the prediction that a lower copy may nevertheless induce an intervention effect if it is fully specified. This possibility becomes a particularly viable line of investigation if we assume, following [17], among others, that uninterpretable features may be valued or unvalued. As a test case, I examined multiple wh-questions under the proposal in $[12,18]$ that successive cyclic wh-movement is triggered by an "edge feature" EF, which may be valued or unvalued.

The crosslinguistic variation discussed above suggests that the hypothesis seems to be on the right track. Languages whose $w h$-elements can be described as being associated with unvalued EFs require multiple $w h$-fronting and do not display superiority effects because the lower copies that could potentially block movement of the other wh-elements are not fully specified (e.g., Serbo-Croatian). Likewise, if the wh-phrases of a given language are obligatorily associated with a valued instance of EF, lower wh-copies do count as proper interveners, which accounts for the fact that some languages simply do not allow multiple wh-questions (e.g., Irish). Finally, we saw that the assignment of an edge feature to a given copy in the course of the derivation may alter its blocking capabilities, which may void superiority effects if the assigned EF is unvalued (e.g., German) or enforce superioritycomplying surface orders if the assigned EF is valued (e.g., Bulgarian).

Admittedly, I have only scratched the surface of the intricacies involving multiple wh-questions and have not discussed many complex paradigms. But the point here is not to provide a full account of multiple wh-questions, but rather a more modest one: to show that we can use the crosslinguistic diversity in the realm of multiple wh-questions as a tool to address the issue of whether lower copies are indeed transparent for movement and agreement across them. To the extent that the broad typology of multiple wh-questions across languages can be accounted for based on the full or partial specification of (lower) copies, the proposal seems worth pursuing.

Funding: This research was partially funded by FAPESP, grant 2017/22560-9.

Institutional Review Board Statement: Not applicable. 
Informed Consent Statement: Not applicable.

Data Availability Statement: Not applicable.

Acknowledgments: I would like to thank Janayna Carvalho, Renato Lacerda, Ezekiel Panitz, and two anonymous reviewers for comments on an earlier version of this paper.

Conflicts of Interest: The author declares no conflict of interest.

\section{References}

1. Chomsky, N. Conditions on transformations. In A Festschrift for Morris Halle; Anderson, S., Kiparsky, P., Eds.; Holt, Rinehart \& Winston: New York, NY, USA, 1973; pp. 232-286.

2. Lightfoot, D. Trace theory and twice-moved NPs. Linguist. Inq. 1976, 7, 559-582.

3. Chomsky, N. Lectures on Government and Binding; Foris: Dordrecht, The Netherlands, 1981.

4. Chomsky, N. A minimalist program for linguistic theory. In The View from Building 20: Essays in Linguistics in Honor of Sylvain Bromberger; Hale, K., Keyser, S.J., Eds.; MIT Press: Cambridge, MA, USA, 1993; pp. 1-52.

5. Chomsky, N. The Minimalist Program; MIT Press: Cambridge, MA, USA, 1995.

6. Nunes, J. Linearization of Chains and Sideward Movement. MIT Press: Cambridge, MA, USA, 2004.

7. Corver, N.; Nunes, J. (Eds.) The Copy Theory of Movement; John Benjamins: Amsterdam, The Netherlands, 2007.

8. Chomsky, N. Minimalist inquiries: The framework. In Step by Step: Essays on Minimalist Syntax in Honor of Howard Lasnik; Martin, R., Michaels, D., Uriagereka, J., Eds.; MIT Press: Cambridge, MA, USA, 2000; pp. 89-155.

9. Chomsky, N. Derivation by phase. In Ken Hale: A Life in Language; Kenstowicz, M., Ed.; MIT Press: Cambridge, MA, USA, 2001; pp. 1-52.

10. Chomsky, N. Beyond explanatory adequacy. In Structures and Beyond; Belletti, A., Ed.; Oxford University Press: Oxford, UK, 2004; pp. 104-131.

11. Nunes, J. On the locus and licensing of edge features. Glossa 2021, 6, 1-35. [CrossRef]

12. Bošković, Ž. On the locality and motivation of Move and Agree: An even more minimal theory. Linguist. Inq. 2007, 38, 589-644. [CrossRef]

13. Sigurðsson, H. Icelandic finite verb agreement. Work. Pap. Scand. Syntax. 1996, 57, 1-46.

14. Schütze, C. INFL in Child and Adult Language: Agreement, Case and Licensing. Ph.D. Thesis, Massachusetts Institute of Technology, Cambridge, MA, USA, 1997.

15. Boeckx, C. Quirky agreement. Studia Linguist. 2000, 54, 354-380. [CrossRef]

16. Halle, M.; Marantz, A. Distributed Morphology and the pieces of inflection. In The View from Building 20: Essays in Linguistics in Honor of Sylvain Bromberger; Hale, K., Keyser, S.J., Eds.; MIT Press: Cambridge, MA, USA, 1993; pp. 111-176.

17. Pesetsky, D.; Torrego, E. The syntax of valuation and the interpretability of features. In Phasal and Clausal Architecture: Syntactic Derivation and Interpretation; Karimi, S., Samiian, V., Wilkins, W., Eds.; John Benjamins: Amsterdam, The Netherlands, 2007; pp. 262-294.

18. Nunes, J. Edge features and multiple wh-questions. Cadernos de Linguística 2021, 2, 1-29. [CrossRef]

19. Rizzi, L. Relativized Minimality; MIT Press: Cambridge, MA, USA, 1990.

20. Huang, C.-T.J. Logical Relations in Chinese and the Theory of Grammar. Ph.D. Thesis, Massachusetts Institute of Technology, Cambridge, MA, USA, 1982.

21. McCloskey, J. Transformational Syntax and Model Theoretic Semantics: A Case Study in Modern Irish; Reidel: Dordrecht, The Netherlands, 1979.

22. Stoyanova, M. Unique Focus: Languages without Multiple Wh-Questions; John Benjamins: Amsterdam, The Netherlands, 2008.

23. Bošković, Ž. On multiple wh-fronting. Linguist. Inq. 2002, 33, 351-384. [CrossRef]

24. Rudin, C. On multiple questions and multiple wh-fronting. Nat. Lang. Linguist. Theory 1988, 6, 445-501. [CrossRef]

25. Haider, H. Towards a superior account of superiority. In Wh-Scope; Marking Lutz, U., Müller, G., von Stechow, A., Eds.; John Benjamins: Amsterdam, The Netherlands, 2000; pp. 231-248.

26. Nunes, J. The copy theory. In The Oxford Handbook of Linguistic Minimalism; Boeckx, C., Ed.; Oxford University Press: Oxford, UK, 2011; pp. 143-172. 